\title{
The wounded blogger: analysis of narratives by women with breast cancer \\ Gerard Coll-Planas ${ }^{1}$ and Mariona Visa ${ }^{2}$
}

\author{
${ }^{1}$ Department of Communication, University of Vic - Central University of Catalonia, Spain \\ ${ }^{2}$ Department of Philology and Communication, University of Lleida, Spain
}

\begin{abstract}
The purpose of this article is to analyse the representation of the body in seven blogs by Spanish women with breast cancer. Using both texts and images, we analyse how they reproduce modern and postmodern logic to represent the wounded body. Based on Frank's proposals, this article draws the conclusion that the women bloggers mainly reproduce the modern logic (characterised by the restitution narrative and a predictable, disassociated and monadic body), but there are elements which break with this logic (the quest narrative, the body presented as associated, dyadic and full of desire, and the acceptance of contingency). After applying Frank's categories, we suggest that the contemporary way of experiencing illness may question the clarity of the modern/postmodern divide.
\end{abstract}

Keywords: cancer, digital public sphere, body, illness, gender

\section{Introduction}

The digital public sphere has become a unique setting for people to share health-related knowledge, either through forums, mailing lists, online self-help groups, institutional web pages, social networks or personal blogs (Gooden and Winefield 2007, Seale 2005, Wentzer and Bygholm 2013). In 2013, it was estimated that at a global level there were around 24,000 indexed blogs which dealt with health-related topics, the majority of which concerned cancer and most particularly breast cancer (Gualtieri and Akhtar 2013).

This proliferation of blogs on cancer tells us that, in the words of Thorne and Murray (2010: 143), cancer has ceased to be a 'dirty secret' and has become a subject about which one can find information and opinions everywhere. Given this context, blogs have become the quintessential tool for developing the 'epochal imperative' of the individuality cult (Remondino 2012: 56), the principle of showing oneself, and the trend to publically share aspects previously considered personal or private, such as living day-to-day with an illness (Visa 2013).

Blogs open up many possibilities for communication: they include photographs and videos, link other blogs or websites and show us how people experience illness on a day to day basis (McCosker 2008). Blogs present relevant differences from other formats: unlike interviews, the person controls what to share, and unlike the memoir, the author cannot predict the evolution of the story, and therefore lacks the distance to be able to provide a coherent narrative. Nevertheless, very little use has been made of blogs as a source for studying how people experience illness (Gualtieri and Akhtar 2013), although there have been a few exceptions such as 
Gualtieri and Akhtar (2013), Keim-Malpass et al. (2013), McCosker (2008), Quinn et al. (2013) and Ressler et al. (2012).

The initial aim of this article was to analyse how illness is represented (textually and graphically) in seven blogs written by Spanish women with breast cancer to determine how they reproduce a modern biomedical reasoning and a postmodern logic, offering new possibilities for empowering, generating knowledge and representing the body (Pitts 2004, Sandell 2008, Seale 2005). However, when the blogs were analysed on the basis of the categories proposed by Frank (1995), it became apparent that the very distinction itself between modern/postmodern needed to be critically challenged.

The following sections set out the theoretical considerations which have guided this article, the field work carried out, the methodology employed and the analysis of the contents of these blogs based on Frank's (1995) analytical categories. In the last section of the analysis, we present a feature of the discourse found in the blogs (language of survival, linked to positive thinking) that may not fit within the modern/postmodern divide. Finally, the conclusions address the aforementioned aim of this article and suggest the need to reflect on the limits of the distinction between modern and postmodern logic as posed by Frank (1995) to account for the present-day context.

\section{Theoretical approach}

The relevance of Frank's (1995) contributions to the field of sociology of health are clearly reflected in recently published articles which continue to use his analytical categories. Examples include, diabetes (Karas and Karner 2005), breast cancer (Pitts 2004, Sumalla et al. 2013, Thomas-MacLean 2004), menopause (Nosek et al. 2012), chronic fatigue syndrome (Whitehead 2006), acquired disability (Smith and Sparkes 2008), fertility problems and lung diseases (Wentzer and Bygholm 2013) and HIV (Avendaño and Palacios 2013).

This article is based on Frank's (1995) distinction between the modern and postmodern ways of experiencing illness, which entail different views regarding the problems of embodiment (control, body-relatedness, other-relatedness and desire) as well as different narrative types (restitution, chaos and quest).

In the modern way of experiencing illness it is 'colonised' by medical knowledge, which involves a 'narrative surrender', since 'the ill person not only agrees to follow physical regimens that are prescribed; she also agrees ... to tell her story in medical terms' (Frank 1995: 6). What we find fostered in this setting is the cultural ideal of a body under control and which can steer clear of death: each individual cause of death can be weathered, put off or avoided (Bauman 1992, Elias 1989, Frank 1995). This characteristic feature is found in the hegemonic breast cancer culture, which is based on 'celebrating survivorhood by downplaying mortality and promoting obedience to medical protocols' (Ehrenreich 2001: 52).

According to Bauman (1992), the modern way to deny body contingency is through the 'language of survival', a constant preoccupation with health and hygiene, which is a widespread concern in breast cancer awareness campaigns (Porroche-Escudero 2014a). Along similar lines, there is an emphasis on the importance of self-control, which in an individualistic social context translates into placing blame on the ill subjects for failing to take care of themselves (Bell 2010, Wilkinson 2001). This trend to burden the individual with the responsibility can be understood as a way of legitimising the neoliberal movements' privitatisation of health services and avoiding having to acknowledge collective responsibility in the issue.

From the modern perspective, the body is characterised in the following terms: predictable (it should be under the subject's control); disassociated (experienced in terms of something 
external, the person has a body); monadic (as an isolated unit); and lacking desire (limited to passively fulfilling medical instructions). In the case of breast cancer, this last feature translates as establishing that 'women's best interests lie in complying with their doctors' orders' (Porroche-Escudero 2014a: 81), which according to Ehrenreich (2001: 52) places women in a child-like position: 'you are encouraged to regress to a little girl state, to suspend critical judgment, and to accept whatever measures the doctors, as parent surrogate, choose to impose'.

In modern logic, experiencing illness is expressed through the restitution narrative: it is the doctor who is considered to have the agency in the cure or treatment, and the aim here is for the patient to return to the state before the illness by means of the treatment. Applying this logic to breast cancer, it is taken for granted that after a mastectomy the aspirations of all women must be to undergo breast reconstruction (Coll-Planas et al. 2013, Sandell 2008).

While the restitution narrative is hegemonic at a cultural level, its antithesis is the chaos narrative: 'In these stories the modernist bulwark of remedy, progress, and professionalism cracks to reveal vulnerability, futility, and impotence' (Frank 1995: 97). In effect, expressing the discourse itself is impossible because the person cannot construct a narrative order or discernible causality.

The postmodern experience of illness begins when people vindicate the ability to give an autonomous account aside from medical discourse. This implies a growing distrust of medicine and that people feel a 'need for a voice they can recognise as their own' (Frank 1995: 7). The postmodern logic follows the quest narrative, in which illness is seen as a challenge which opens up the way to new experiences from which one can learn and share with others. The body is presented as: contingent, accepting that it is not (nor can it be) under the complete control of the subject; associated, the individual feels associated with their body (they are body); dyadic, that is, in relation to other bodies, with the illness as the basis from which to create links with others; and productive at the level of desire.

Frank's (1995) categories have been applied in the analysis of the blogs taking into consideration that modern and postmodern logic, narrative types and problems of embodiment can be combined in the same blog. Therefore, the blogs, rather than reflect an inner coherence, in fact combine different positions regarding these issues.

\section{Methodology and field work}

The corpus of analysis comprises blogs written by Spanish women with breast cancer, and which deal specifically to this topic. The sample was based on first exploring the internet through google and blog communities. A total of 13 blogs met these requirements (in March 2014). The blogs were ordered according to the number of published entries and then analysed, starting with the one with the highest number of entries and working down. The selection process ended, following the criterion of saturation sampling, when new discourses no longer appeared. Accordingly, seven blogs were selected which, taken together, totalled 597 entries (see Table 1).

All the bloggers reside in Spain, are in their thirties or forties, university graduates and hold qualified professional positions. The aim behind writing their blogs was to share experiences, reflections and advice. The exception was blog 7, conceived as a collective political project aimed at questioning the dominant heterosexist discourse on breast cancer. In all cases, the blogs are aimed at a mixed audience composed of people from their own circles, other women who have been affected or people they do not know.

From the blogs selected, both texts and photographs were analysed. All the text entries were transferred into an Excel matrix (Meyer and Avery 2009) and codified according to the 
Table 1 Sample of blogs studied

\begin{tabular}{llllll}
$N$ & Title of blog & Author Age & Period active & No. entries & $\begin{array}{l}\text { No. entries } \\
\text { with photographs }\end{array}$ \\
\hline 1 & Memorias de un cáncer de mama & 31 & $2010-$ present & 133 & 51 \\
2 & Una sonrisa y mil pañuelos & 33 & $2011-$ present & 108 & 76 \\
3 & Breast cancer, mi maestr@ & 28 & $2008-$ present & 84 & 17 \\
4 & Blog de María Antonia Valdivielso & 40 & $2008-2009$ & 81 & 27 \\
5 & iSí sin mis pechos! & 45 & $2008-2010$ & 79 & 70 \\
6 & Sobrevivir & 33 & $2011-$ present & 75 & 35 \\
7 & Marimachos Cancerosas & $30-45$ & 2013-present & 37 & 37 \\
\hline
\end{tabular}

${ }^{1}$ Age when they began the blog.

${ }^{2}$ In the case of the blogs which are no longer updated, are kept visible in cyberspace.

analytical categories shown in Table 2. Given the space limits, we cannot provide detailed explanations of the categories, but we include an example of the interpretation of each one.

Once the categories were established, both authors of the article coded the first 15 entries of each blog and checked for discrepancies in order to maximise a solid base for coding the information. The resulting criteria were used as a basis for coding the rest of the entries.

After this, two types of analysis were drawn up. First the entries were analysed on an individual basis. Second, the narrative structure of each blog was analysed, which allowed us to acknowledge how the different types of narratives and embodiment problems were combined and evolve in the time span that the blog was updated. However, this part of the analysis is not developed here due to space limits and will be tackled in a future article.

As regards the photographs, 181 were analysed in which the body appears (of the authors themselves or of others). These were classified on the basis of narrative categories and embodiment problems, as well as on descriptive, compositional and social representation criteria (Visa 2012). Descriptive analysis focused on the blog header iconic elements, the number of photographs for each post, its origin and whether they were accompanied by captions or text. The compositional analysis and the social representation provide information about the main image elements and the context of the photograph.

Although these blogs are public, we informed those authors who provided contact information (five of the seven) of the research we were carrying out, sent them a preliminary version

Table 2 Categories of analysis

\begin{tabular}{|c|c|c|}
\hline & Modern logic & Postmodern logic \\
\hline Narrative & $\begin{array}{l}\text { Restitution (colonised by medical } \\
\text { rationality, aimed at returning to } \\
\text { the previous state) } \\
\text { Chaos as antithesis (express futility, anger, fear) }\end{array}$ & $\begin{array}{l}\text { Quest (vindication of autonomy from } \\
\text { medical rationality, illness as a } \\
\text { challenge) }\end{array}$ \\
\hline \multirow[t]{4}{*}{$\begin{array}{l}\text { Problems of } \\
\text { embodiment }\end{array}$} & Predictable (under subject's control) & $\begin{array}{l}\text { Contingent (accepting it cannot be } \\
\text { under subject's control) }\end{array}$ \\
\hline & Dissociated (having a body) & Associated (being a body) \\
\hline & Monadic (isolated unit) & Dyadic (in relation to others) \\
\hline & $\begin{array}{l}\text { Lacking desire (limited to following } \\
\text { medical recommendations) }\end{array}$ & $\begin{array}{l}\text { Productive desire (will to carry out } \\
\text { other activities apart from treatment) }\end{array}$ \\
\hline
\end{tabular}


of the article and offered the option of making their blog anonymous. Of those who replied (four of the five contacted), all agreed that we could cite their blog without the need for anonymity. We also received permission for the use of the images included in the article.

The article was originally written in Spanish, and included quotations of quotes from the blogs which were also in Spanish. The translation was carried out by a professional translator who was given a clear brief to not only maintain the style and register required for academic publications for the main body of the article, but also to reproduce the style and tone, often informal or colloquial, of the blogs themselves. The final version was then revised by the authors to ensure the accuracy of the translation.

\section{The modern logic: medicine at the service of recovery}

This section analyses how the women bloggers adopt the modern logic in terms of how they position themselves in relation to the problems of embodiment and the way they narrate the process. To start with, it should be pointed out that the blogs analysed mainly reproduce the modern medical logic: the bloggers legitimise the health professionals, make extensive use of medical vocabulary and display their trust in medical knowledge (Clarke and Everest 2006). In blog 1, there are numerous entries with links to news about advances in medicine and the author goes to great lengths to provide information about scientific knowledge. Of the photographs she shares, some 75 per cent stress prevention and diagnosis, or show people who have survived the illness (Atkinson and Rubinelli 2012). Bloggers are in fact fed by the promise of continued medical advances: 'Science is advancing in leaps and bounds' (blog 6); 'Everyday there are better treatments' (blog 1).

These bloggers often express their gratitude to the health professionals: 'these amazing professionals who take care of us, pamper us and give us back our life' (blog 2); 'I couldn't be more grateful for feeling that they have saved my life' (blog 3). There are bloggers who state that the role of the patient is to follow the doctors' instructions; the author of blog 4, for example, explains that when she knew her diagnosis, she thought, 'I've no choice but to face up to it and do whatever they tell me to be cured'. In 27 photographs we can see the bloggers passively receiving treatment or listening to the doctors (see image 1). The active subject is, therefore, the medical team or the treatment itself, thus showing a body bereft of its own

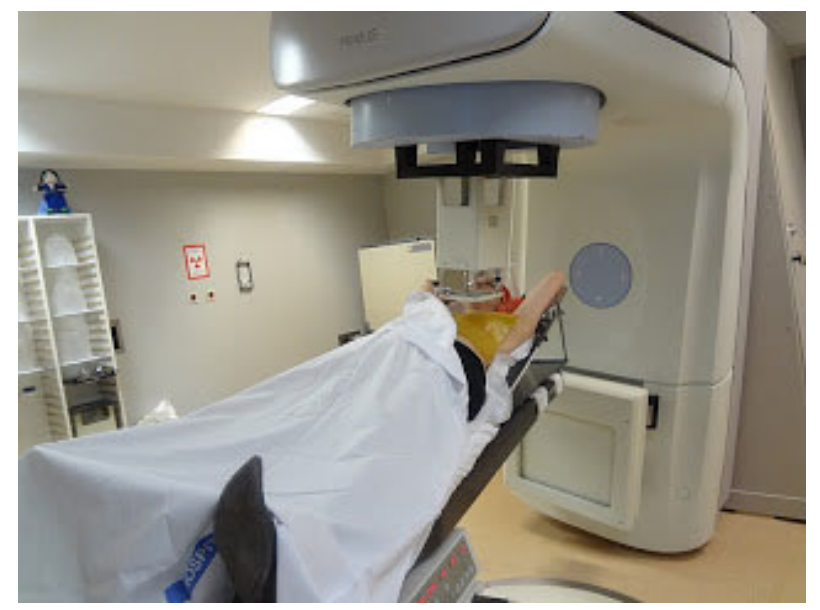

Image 1 Image from the blog "Una sonrisa y mil pañuelos" 
autonomous desire other than that of taking on board the doctors' orders as their own (Ehrenreich 2001, Porroche-Escudero 2014a).

Another characteristic feature of the modern logic is to see the body as being disassociated, something one has and is external (Frank 1995). Although, as we will see in the next section, in the majority of the blogs experiencing the illness translates into a greater bonding with the body, on occasions it also appears as disassociated from the subject. This reaction is sometimes due to perceiving the body as a threat to their life (Frank 1995). For example, one of the authors (blog 7), faced with the possibility of losing her breast, explains: 'I take care of the injured breast as if it were an abandoned cat'. The author of blog 5 gives the following account of the relationship with her body while waiting for a mastectomy:

Without being aware of it, I didn't palpate my breasts for many days. (...) I wasn't going to lose my breasts in the operation. I didn't lose them when they said I had breast cancer. I lost them the moment my mind said that if they stayed they'd kill me. (blog 5)

Once the bilateral mastectomy had been performed and the new prosthesis implanted, she continues stating that she feels mutilated, that she does not feel that the reconstructed breasts are her own ('To me they feel like two balls stuck to my body') and she is unable to look at her body in the mirror. This disassociation tones down nine months after the mastectomy, when she manages to feel her breasts: 'My breasts and I have started to get to know each other and be friends. I'm sure we're going to get on well. I'm no longer afraid of them' (blog 5). As this quote illustrates, although she explains how she is moving towards accepting the change to her body, she continues to talk of her breasts as disassociated.

Turning to the graphic representations, the disassociated body appears in photographs which show a fragmented body. Of the 61 photographs which show the effects of the treatment in detail, in 44 the body appears in close ups of the different affected parts of the body (see image 2). These photographs are influenced by medical photographs because the main aim is to show the physical state of the body, but they differ from the ones in medical manuals in that they neither hide the face of the patient nor are taken against an abstract background.

The modern restitution narrative appears in blogs in the desire to recover 'normality' and control over the body. What prevails is the ideal of having a predictable body, unaffected by the contingencies that are the result of the illness and its treatment. This takes a clear form in

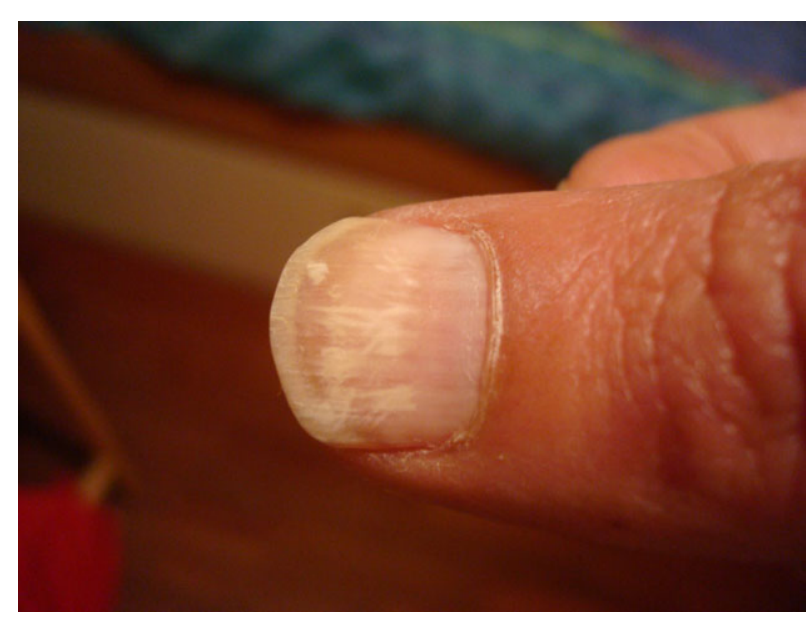

Image 2 Image from the blog "Sí sin mis pechos" 
blogs 2 and 4, particularly in the desire to have a body that can keep up the same pace of work as before the illness. The author of blog 2 poses her process in terms of a fight against cancer to gain control of her body: 'Some time ago now you stopped my life and for a time you held the reins; but I'm back to take charge of what you should never have taken from me'.

The majority of the posts illustrated with photographs of the authors abide by the restitution logic. The before and after photographs fall within this narrative, since photographs of the illness are compared with those of their recovery in which the body is once again predictable, without the marks and traces left by the illness and treatment. Only blogs 2, 5 and 6 are illustrated with photographs showing the treatment process, but they do so from the restitution narrative, since rather than accepting contingency they illustrate the treatment process aimed at returning them to their state prior to the illness.

The restitution logic is also seen in the fact that the majority of the bloggers stop updating their blog 'once the cycle has come to an end' (blog 4). Accordingly, it implies that the diagnostic and treatment process has been a fenced-off period in time and is now over.

\section{The postmodern logic: challenging the way of understanding the illness}

As regards reproducing the postmodern logic in these blogs, we will begin by tackling the embodiment problems of desire, body-relatedness and other-relatedness, and then move on to analysing the presence of the quest narrative, which is very closely related to accepting the contingency of the body.

The aspect of productive desire is particularly visible, mainly due to the type of data being analysed: writing and maintaining blogs is already in itself an expression of the desire to narrate, to make sense of their suffering, to share their experience and establish their way of seeing the process they are going through (Frank 1995, Karas and Karner 2005, Mathieson and Stam 1995, Thorne and Murray 2010). Accordingly, one of the authors states that her blog has become 'her main driving force' (blog 2), and another makes it clear that the messages she receives 'are like a charge of electricity; they give me strength, they make me feel alive and above all that everything I've gone through has not been in vain' (blog 1). In fact, aside from creating blogs, being diagnosed with cancer encourages their desire to carry out projects: 'a thousand things come to mind that you still haven't done and you'd like to do before you kick the bucket' (blog 6). The productive desire is also illustrated in the will to take on projects and activities in parallel to convalescence and treatment, as seen in a blog about handicrafts by the author of blog 3; the travels of the authors (blogs 4 and 6); the interest in getting back to working life (blogs 2 and 4); or the collective projects they take part in.

Within this context, the main author in blog 7 tries to search for her desire away from the medical imperatives permeated with a heterosexist logic, which construct women in terms of pleasing men (Broom 2001). Being a doctor herself, she does not share photographs from the medical setting nor the treatment, she decides not to reproduce medical language and is the only blogger who shows a confrontation with health professionals. This happened after a mastectomy, when she decided she did not want a breast reconstruction, but instead to have the other removed:

The Spanish National Health Service saved me from cancer, but on the other hand they were imposing a normative body on me. The mastectomy (removing the breast) for 'aesthetical reasons' is not possible; the only option is a silicon implant (maintaining the body binomial is the 'aesthetics' of the health service). They victimise my situation ('the cancer has 
affected you; you'll most certainly want to see yourself later with your breasts') and they impose a body on me. (blog 7)

The request to reject reconstruction and ask for a mastectomy of the other breast (without a health risk prevention justification), is 'unthinkable' or considered to be 'irrational' in mainstream discourse, despite the fact that it is the will of some affected women (Sandell 2008: $334,339)$.

Turning to body-relatedness, going through the experience of illness tends to lead authors to connect more with their body, particularly in the cases of blogs 1, 3, 6 and 7:

Before, I hardly ever listened to my body ... I was deaf to it. Now my senses are awake, I listen to my body and try to give it what it asks for to find a balance and to feel healthier. (blog 1)

From a less individualist reading, one author in blog 7 states that we live in a culture where embodiment is denied and, for her, cancer has been an opportunity to understand its importance. Her experience leads her to wanting to 'embody' her social relationships, her desire, her work and her activism, by referring to her wish to make the relevance of the body evident in these spheres.

As regards the other-relatedness dimension, we mainly find a dyadic conception of the body, since writing a blog expresses their wish to communicate, to share their body experience with people from their own circles or strangers. Apart from the act of writing a blog itself, the dyadic relationship with others is present in three aspects examined following: the importance of the other's viewpoint, to see oneself as an interdependent subject and illness as a process which generates empathy and solidarity.

First, as regards the other's viewpoint, a persistent theme is worrying about no longer being desirable as a result of the effects of chemotherapy (especially loss of hair), the scars or the mastectomy. The need to feel desirable translates into wanting to dress up and share advice, reflections on and experiences concerning how they can improve their appearance (Sumalla et al. 2013). As the bloggers themselves explain, the wish to erase or cover up bodily traces of the cancer and its treatment is not only due to the need to please others but also to escape from the stigma attached to cancer which results from hair loss or wearing a headscarf to cover their head. In relation to the appearance of the breasts, frequent instances of their concern to have desirable breasts are in stark contrast with the fact that only once, in blog 5 , is there any mention of concern for the loss of erogenous pleasure in this part of the body. This reflects the importance given to aesthetics for women's wellbeing in the breast cancer awareness discourse (Porroche-Escudero 2014a) and that, in an androcentric context, the masculine viewpoint of the breast is given priority over the woman's ability to feel erogenous pleasure through her own breasts (Coll-Planas et al. 2013, Millsted and Frith 2003, Smith 2009, Thorne and Murray 2010).

Second, in the blogs the dyadic body appears when references are made to the illness process and treatment, not as an individual but a relational experience. Along these lines, acknowledging people who have been by their side in the process is a very predominant theme in these blogs. The tendency to explain the process as something relational is a particular characteristic of the way women narrate illness, as opposed to men, who tend to come to terms with themselves on their own and find it more difficult to acknowledge interdependence (Pitts 2004, Potts 2000, Seale 2002). The blogs end up becoming a network around the author (Reig 2012), which is referred to as 'my cyberfamily of fighters' (blog 2), or as a 'brotherhood' (blog 4). This idea is found particularly in blogs 7 and 2: 'Now I can't go to bed without knowing if my hairless crew are well, or getting by ... but we are there for each other' (blog 2). 
Third, the blogs also illustrate how living through the illness leads to some authors becoming involved in collective projects: events organised by associations against cancer, political protests or photography projects to give visibility to the illness. Blog 7 itself starts out as a collective proposal to criticise the dominant discourse on breast cancer for 'selling cancer as an individual problem without considering its environmental impact', for being heterosexist and for using this illness for advertising purposes.

Although the dyadic logic can be clearly found in the texts, it is only partially visible in the photographs: the majority of those studied (83) show the blog author on her own, in contrast to the 47 in which they appear with friends and relatives. As the author of blog 2 makes quite clear, this gap is likely due to respecting the image rights of others rather than not wanting to show them.

Moving on to the quest narrative (the postmodern way of explaining and making sense of this illness), this appears when cancer is presented as an experience which brings positive aspects with it: that the illness has guided them towards listening to their body, or that the illness has made them live for the moment: 'cancer can open our eyes by revealing the brevity of life, and a cancer diagnosis is capable of giving back to us savouring life' (blog 1). Another very commonly expressed idea is that cancer has taught them a lesson: 'I'll never be happy for having had cancer, but the lesson ... is the purest and most profound that I will ever be able to experience' (blog 2). They talk of cancer in terms of a 'gift' (blog 2), as 'my teacher' (blog 3) and even give thanks for having transformed them into better people.

As opposed to the restitution narrative, in the quest narrative it is assumed that there is no going back. The author of blog 2 accepts that she has 'some limitations with which one has to live', and refers to 'what I'll never be either physically or mentally'. Acknowledging these losses lives alongside assessing positive changes that are the result of cancer: in her case, it leaves an indelible mark that links her to a community and collective battles which do not end when her treatment is over. Along similar lines, the author of blog 1, states, with hindsight, that 'there are things which can't be recovered and I don't want to recover either; things left along the way'. She stresses that she does not want to recover her life but rather 'reconquer' it, breaking with the restitution logic and posing the illness as a challenge.

We find the clearest case of vindicating change in blog 7, in which the main author explains that after the mastectomy s/he finally feels s/he is in her/his 'own' body: 'the fact is that I feel hunky dory in my body!!! I never felt either man or woman ... now my body is also like this!!!!' (blog 7). So, rather than wanting to go back to her/his previous state, the mastectomy became the path which leads to the author feeling that the body is her/his own.

Another key characteristic of the quest narrative is accepting the contingency of the body. This translates, for example, into seeing the scars as a mark of what they have been through, something that they cannot, nor want to, forget. So, they claim them as proof of what 'I have fought against, conquered and survived' (blog 6), and as a reminder: 'I promise I'll always be proud of my scars (these which I still can't look at without feeling a little apprehensive)' (blog 2). One author of blog 7 states: 'I refuse to silence my scars to hide the existence of death', and, in fact, in the first post on the blog as a declaration of intentions, she shows a photograph in which you see her torso after the mastectomy (see image 3). She follows the ideas proposed by authors like Lorde (1980), who denounced attempts to erase traces of the cancer in subjectivity by means of surgically reconstructing breasts and trying to eliminate the scars (also in Porroche-Escudero 2013, Wilkinson 2001, Thorne and Murray 2010). Along these lines, various blogs echo the Costuras a flor de piel and The Scar Project photography projects, which portray women showing their breasts after the surgical intervention, in fact the author of blog 1 participated as a model. The mainstream strategy to make the effects of cancer and its treatment on the body invisible is criticised in the following manner: 'I think the people prefer to pin a pink bow on us and 


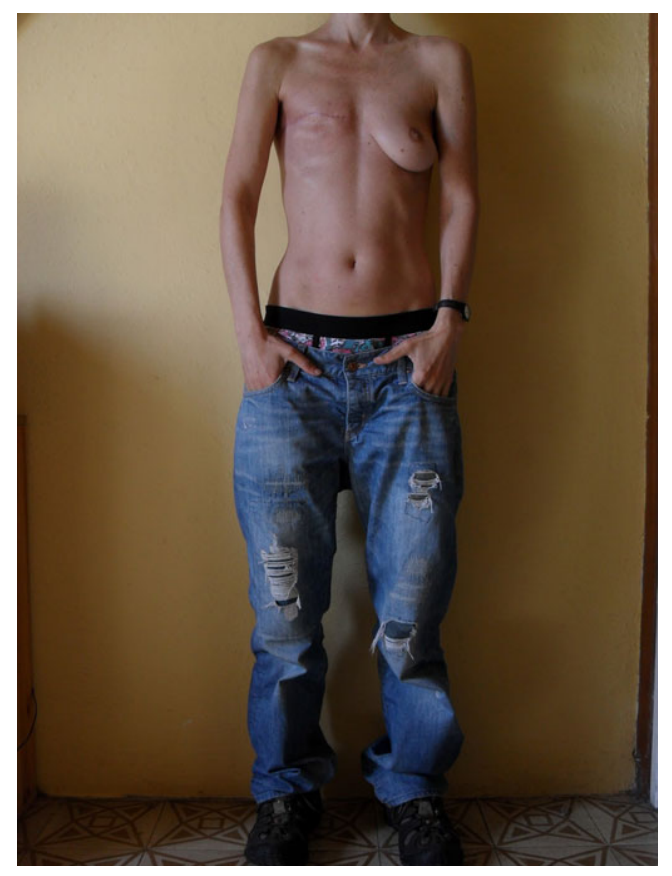

Image 3 Image from the blog "Marimachos cancerosas"

package us up like a cuddly toy rather than see that cancer leaves its mark' (blog 1). These representations break with seeing post-mastectomy breasts as 'obscene' or 'shameful' (Broom in Wilkinson 2001: 271).

We also find acknowledging contingency in other aspects: the widespread practice of cutting off their hair before it falls, in some cases turning this into a social event; vindicating the use of the headscarf instead of a wig to make cancer visible in public spaces and sharing aspects considered to be negative such as tiredness, desperation or fear of death.

However, the most radical acceptance of the contingency of the body is to accept its finite and mortal nature, which is something the dominant culture tries to deny (Bauman 1992). In fact what is striking is how little death is talked about directly, although it is often implied, particularly in cases of aggressive or recurring tumours. When it is mentioned, in the majority of the blogs, the authors do so by avoiding direct references ('expiration date', blog 2) and it is only represented indirectly on two occasions with photographs of women who have died as a result of the illness. Blog 7 once again proves to be the exception as it is the only one which tackles the topic of mortality in a very direct manner. In fact the most prolific author in this blog signs herself as Dr. Corpse (Dra. Cadáver) and believes that one of the positive aspects of cancer is that it has made her aware of this mortal coil:

A cancer diagnostic is a gift. It reminds us we're going 2 die. If we survive, it gives us the courage to wipe out the silly things from our lives; whatever life we lead after cancer, the diagnostic has forced us to raise the question of not $2 \mathrm{~B}$, the end. It's a wonderful chance. It's a blessing. (blog 7)

In the same blog we can even find a photograph which shows one of the authors performing a parody of her own death. 


\section{Blurring the divide between modern and postmodern logics?}

Another aspect which crops up a good deal in the blogs is the 'language of survival', which Bauman (1992) sees as the modern form of negating mortality. However, the analysis of how this is expressed calls to question the distinction between modern and postmodern logic proposed by Frank (1995).

The language of survival (Bauman 1992) appears very clearly in these blogs, questioning the passive attitude but without questioning medical logic. Accordingly, stress is put on what they themselves can do to favour the cure through alternative therapies (which they see as complementary to conventional medicine) and changes to their diet, style of life and emotion management. The language of survival is particularly visible in blogs 1 and 3, whose authors practice yoga, sports, are careful with their dietary intake, turn to alternative therapies and read and recommend self-help books.

Making changes that are within their grasp to aid the treatment process can be interpreted as a reaction to the feeling of being powerless as a result of being completely dependent on medical intervention. Along these lines, and particularly illustrative, is when the author of blog 3 explains the moment she decided to stop looking for information about her illness on the internet:

I don't want, neither am I ready, to read things over which I have no control; which I have no idea how to interpret and I'd certainly end up interpreting ... for the worse and getting it wrong. So for the first time in my life as a cancer patient I have decided ... TO BE A LITTLE BIT IGNORANT ABOUT MINE!!! . . this as a first step ... the second is to stop smoking now and the third is to move my butt along the seafront to lose these 3 kilos I've put on. (blog 3)

So, faced with being unable to fully grasp the medical information, she decides to exercise influence on those changes within her reach: habits and life style.

In this context the ideology of positive thinking (Held 2002) makes a strong appearance. According to this way of thinking people are responsible for their recovery "by developing a more adaptive "coping style" -in particular one that emphasises "positive" (...) thoughts and attitudes' (Wilkinson 2001: 273). This ideology is particularly visible in blogs 1, 2, 3 and 5 . In blog 3, for example, we find statements like: "we are entirely responsible for all of our experiences'; and 'Repeat to yourself ten times a day "I'm healthy" and forget you have cancer'. According to authors such as Bell (2010), Held (2002) and Pitts (2004), this discourse constitutes a false empowerment because it holds the subject responsible up to limits which are beyond their control. In addition, it makes it difficult to accept the contingency of the body and the negative effects of the illness and treatment (Porroche-Escudero 2014b). We find an example of denying information that cannot be taken on board in blog 1 , when the author is informed that she has premature menopause, and states: 'How do you take in a piece of news like that? Well straight off you don't; you ignore it, because I'm 32 and I refuse to live a state of physical maturity that doesn't apply to me'.

A consequence of the positive thinking that we can identify in the blogs is the resistance to acknowledging the negative side of the illness, which is in line with the cultural resistance to the chaos narrative identified by Frank (1995) and Norrick (2005). In addition, reluctance to show the negative side of the process is because we are analysing blogs so their authors select the experiences and emotions they want to share. Following the trend of the mainstream breast-cancer culture (Ehrenreich 2001), only on very rare occasions do the authors openly admit that they have felt 'weak, mortal and lost in an unknown world' (blog 3), or claim they 
have the right to 'get angry, cry, make a fuss or get furious' (blog 2). It is blog 5 which contains the clearest indications of the chaos narrative. On many occasions the author writes that she feels strange, run down and shows her body in detail, highlighting in particular those areas most affected (loss of hair, scars, etc.).

Generally, when something negative appears in the blogs the authors try to shift this towards a positive direction:

Tomorrow I have another chemo session, the fourth of six, so that means I'm on the countdown!! Everyone around me says to just think about it almost being over ... and I just think about not wanting to go!! I'm human after all ... I'm sorry but it's getting difficult for me ... but anyway, I'm going to exercise some positive thinking and see the glass as half full. (blog 2)

This is one of the examples which illustrates Ehrenreich's (2001: 48) statement that in the breast cancer culture 'unhappiness requires a kind of apology'. So a characteristic of contemporaneity, as already seen in section 2 , is transferred to the breast cancer culture.

These difficulties to take on the negative aspects of the process on occasions are attributed to not wishing to create problems in their immediate surroundings: "we owe it to those around us to make as big an effort as possible to put on a good face' (blog 2). This is a feature related to the feminine imperative of having to be in a position to take care of others, a characteristic that is not so common in men's narratives about illness (Potts 2000, Seale 2002, Thorne and Murray 2000). Some authors clearly explain the difficulties they find in their surroundings to allow themselves to share the negative aspects, an aspect which is also found in Frank (1995), Smith and Sparkes (2007), Sumalla et al. (2013), Thomas-MacLean (2004) and Wilkinson, (2001). The author of blog 6 explains the reaction of a neighbour to her blog along these lines: 'she told me she's sick and tired of reading sad things ... Friday she said to me "I'm sure being ill also had good things about it; not everything can be bad". So I promised her that I would make a list of all the good things when you're in this situation' (blog 6).

From our point of view, the language of survival (with positive thinking as one of its dimensions) does not fit in the modern and postmodern categories as defined by Frank (1995). On the one hand, the modern logic is not reproduced strictly speaking, since agency does not revolve exclusively around the doctors but rather those who are ill hold themselves responsible for their cure through changes to their life style, which includes a mandate to maintain a positive and desiring attitude which is not included in Frank's definition of the modern way to experiencing illness. Furthermore, in the current context there is pressure to give meaning to the process one lives through and to make it public, which is also a far cry from modern logic.

On the other hand, the current discourses do not follow Frank's postmodern perspective in the strict sense either: they do not distance themselves from the medical rationality and, although they pose illness as a challenge, they are not able to openly accept the contingency of the body.

\section{Conclusions}

In a given blog, and even a same post, we can find different types of narratives and positions regarding embodiment problems (Frank 1995, Nosek et al. 2012). So, these blogs are a complex blend of modern and postmodern logic. 
Faced with the question whether blogs allow for generating new imaginaries about the wounded body, the answer is ambivalent. On the one hand, the majority of the blogs studied here reproduce the modern logic: there is a search for the predictability of the body and its restitution, they try to hide the side effects, they do not take on board mortality, and there is an acceptance of medical logic. In addition, although less frequent, the body appears monadic and disassociated, and women take on a passive role in which their will is reduced to obeying the dictates of the doctors.

On the other hand, there are some significant features of the postmodern perspective: a desiring body, with projects which go beyond following medical advice; a body understood as a nodule in a network of affect, care and solidarity; and the acceptance and visibility of the bodily traces of what they have gone through. These characteristics are most clearly reflected in blog 7, the only one which completely ousts medical logic and gives more emphasis to the body as dyadic, associated and contingent.

After analysing how the blogs reproduce the modern and the postmodern logic proposed by Frank (1995), we believe that this analysis leaves room for questioning this very distinction. In our view, the author's distinction between modern and postmodern logic could be critically revised, since it perhaps cannot account for the present hegemonic logic of the language of survival, which strictly speaking would not follow either the modern or postmodern logic in Frank's terms. In the current context, stress is put on the importance of self-control and individual responsibility as regards life style (physical activity, eating habits, managing emotions, etc.) in that cancer is seen in terms of 'a failure of the self to take care of itself' (Bell 2010: 350).

Bauman's language of survival, which pervades the blogs, blends both modern and postmodern characteristics (see section 6). This leads us to calling to question and revising Frank's (1995) description of modern and postmodern logics so that they would be able to account for the complexity of the current context, which perhaps they are now unable to capture properly.

Address for correspondence: Gerard Coll-Planas, Department of Communication, University of Vic - Central University of Catalonia, cl Sagrada Familia 7, 08500 Vic, Spain. E-mail: gerard.coll@uvic.cat

\section{References}

Atkinson, S. and Rubinelli, S. (2012) Narrative in cancer research and policy: voice, knowledge and context, Critical Reviews in Oncology/Hematology, 84, 2, 11-6.

Avendaño, A.M.A. and Palacios, M.D.F.F. (2013) Trato de remar contra la corriente: narrativas del padecimiento de personas que viven con VIH en México, Revista Uaricha, 10, 22, 97-113.

Bauman, Z. (1992) Mortality, inmortality other life strategies. Stanford, CA: Stanford University Press.

Bell, K. (2010) Cancer survivorship, mor(t)ality and lifestyle discourses on cancer prevention, Sociology of Health \& Illness, 32, 3, 349-64.

Broom, D. (2001) Reading breast cancer: reflections on a dangerous intersection, Health, 5, 2, 249-68.

Clarke, J.N. and Everest, M.M. (2006) Cancer in the mass print media: fear, uncertainty and the medical model, Social Science \& Medicine, 62, 10, 2591-600.

Coll-Planas, G., Alfama, E. and Cruells, M. (2013) Se_nos gener@ mujeres, La construcción discursiva del pecho femenino en el ámbito médico, Athenea Digital, 13, 3, 121-35.

Ehrenreich, B. (2001) Welcome to cancerland, Harper's Magazine, November, 43-53.

Elias, N. (1989) El proceso de la civilización. Investigaciones sociogenéticas y psicogenéticas. Madrid: Fondo de Cultura Económica.

Frank, A. (1995) The wounded storyteller. Body, illness, and ethics. Chicago: The University of Chicago Press. 
Gooden, R.J. and Winefield, H.R. (2007) Breast and prostate cancer online discussion boards, A thematic analysis of gender differences and similarities, Journal of Health Psychology, 12, 1, 103-14.

Gualtieri, L. and Akhtar, F.Y. (2013) Cancer patient blogs: how patients, clinicians, and researchers learn from rich narratives of illness. Proceedings of the ITI 2013 35th International Conference on Information Technology Interfaces, 24-27 June 2013, Cavtat, Croatia.

Held, B.S. (2002) The tyranny of the positive attitude in America: observation and speculation, Journal of Clinical Psychology, 58, 9, 965-91.

Karas, J. and Karner, T.X. (2005) Understanding the diabetic body-self, Qualitative Health Research, 15, 8, 1086-104.

Keim-Malpass, J., Baernholdt, M., Erickson, J.M., Ropka, M.E., et al. (2013) Blogging through cancer: young women's persistent problems shared online, Cancer Nursing, 36, 2, 163-72.

Lorde, A. (1980) The cancer journals. San Francisco: Aunt Lute Books.

Mathieson, C.M. and Stam, H.J. (1995) Renegotiating identity: cancer narratives, Sociology of Health \& Illness, 17, 3, 283-306.

McCosker, A. (2008) Blogging illness: recovering in public, M/C Journal, 11, 6.

Meyer, D.Z. and Avery, L.M. (2009) Excel as a qualitative data analysis tool, Field Methods, 21, 1, 91112.

Millsted, R. and Frith, H. (2003) Being large-breasted: women negotiating embodiment, Women's Studies International Forum, 26, 5, 455-65.

Norrick, N.R. (2005) The dark side of tellability, Narrative Inquiry, 15, 2, 323-43.

Nosek, M., Kennedy, H.P. and Gudmundsdottir, M. (2012) Chaos, restitution and quest: one woman's journey through menopause, Sociology of Health \& Illness, 34, 7, 994-1009.

Pitts, V. (2004) Illness and Internet empowerment: writing and reading breast cancer in cyberspace, Health, 8, 1, 33-59.

Porroche-Escudero, A. (2013) Luces y Sombras de la reconstrucción mamaria, MYS: Mujer y Salud, Revista de Comunicación Interactiva, 34, 1, 30-3.

Porroche-Escudero, A. (2014a) Perilous equations? Empowerment and the pedagogy of fear in breast cancer awareness campaigns, Women's Studies International Forum, 47, 1, 77-92.

Porroche-Escudero, A. (2014b) The 'invisible scars' of breast cancer treatments, Anthropology Today, 30, $3,18-21$.

Potts, L.K. (2000) Publishing the Personal: autobiographical narratives of breast cancer and the self. In Potts, L.K. (ed.) Ideologies of breast cancer: feminist perspectives. London: Macmillan.

Quinn, E.M., Corrigan, M.A., McHugh, S.M., Murphy, D., et al. (2013) Who's talking about breast cancer? Analysis of daily breast cancer posts on the internet, The Breast, 22, 1, 24-7.

Reig, D. (2012) Socionomía. ¿Vas a perderte la revolución social? Barcelona: Deusto ediciones.

Remondino, G. (2012) Blogs y redes sociales: un análisis desde las tecnologías de la gubernamentalidad y el género, Athenea Digital, 12, 3, 51-69.

Ressler, P.K., Bradshaw, Y.S., Gualtieri, L., Chui, K.K.H., et al. (2012) Communicating the experience of chronic pain and illness through blogging, Journal of Medical Internet Research, 14, 5, e143.

Sandell, K. (2008) Stories without significance in the discourse of breast reconstruction, Science, Technology Human Values, 33, 3, 326-44.

Seale, C. (2002) Cancer heroics: a study of news reports with particular reference to gender, Sociology, $36,1,107-26$.

Seale, C. (2005) New directions for critical internet health studies: representing cancer experience on the web, Sociology of Health \& Illness, 27, 4, 515-40.

Smith, B. and Sparkes, A.C. (2008) Changing bodies, changing narratives and the consequences of tellability: a case study of becoming disabled through sport, Sociology of Health \& Illness, 30, 2, 217-36.

Smith, C.P. (2009) The politics of the marked body: an examination of female genital cutting and breast implantation. PhD thesis, University of Oregon.

Sumalla, E.C., Ochoa, C. and Blanco, I. (2013) 'Pero... ¿estoy curada?'. Narración de restitución y discurso biomédico en breast cancer. In Martínez-Hernández, À., Massana I. and Digiacomo, S.M. (eds) Evidencias y narrativas en la atención sanitaria. Una perspectiva antropológica. Tarragona / Portoalegre: Publicacions de la URV and Rede Unida. 
Thomas-MacLean, R. (2004) Understanding breast cancer stories via Frank's narrative types, Social Science \& Medicine, 58, 9, 1647-57.

Thorne, S.E. and Murray, C. (2010) Social constructions of breast cancer, Health Care for Women International, 21, 3, 141-59.

Visa, M. (2012) Una metodología sociológica y narrativa para el análisis de relatos fotográficos, Estudios Sobre el Mensaje Periodístico, 18, 929-39.

Visa, M. (2013) L'àlbum fotogràfic familiar. Un retrat socialitzat de la pròpia vida. Lleida: Publicacions UdL.

Wentzer, H.S. and Bygholm, A. (2013) Narratives of empowerment and compliance: studies of communication in online patient support groups, International Journal of Medical Informatics, 82, 12, 386-94.

Whitehead, L.C. (2006) Quest, chaos and restitution: Living with chronic fatigue syndrome/myalgic encephalomyelitis, Social Science \& Medicine, 62, 9, 2236-45.

Wilkinson, S. (2001) Breast cancer: feminism, representations and resistance - a commentary on Dorothy Broom's reading breast cancer, Health, 5, 2, 269-77. 